\title{
The Mobile Monitoring ANd CONTROL OF REAL Systems
}

\author{
Matýsek Miroslav, Adámek Milan, Karafiát Tomáš \\ Tomas Bata University in Zlin, Department of Computer and Communication System \\ Nad Stráněmi 4511, 76005, Zlín
}

\begin{abstract}
The task of this work was to design and realize a remote real system monitoring and control with the help of a mobile or smart phone in the client/server structure. The client segment running in a mobile or smart phone with LTE, UMTS or GSM GPRS/EDGE was realized in the JME environment. Internet data transfer is supported by a TCP/IP protocol. The server segment was created in JSE on a PC with a simple desktop application for remote control from a PC used to control the real system and its optional local manual control.
\end{abstract}

Keywords: Mobile monitoring; Mobile control; Real system; Java; Matlab; LTE; UMTS; GPRS/EDGE
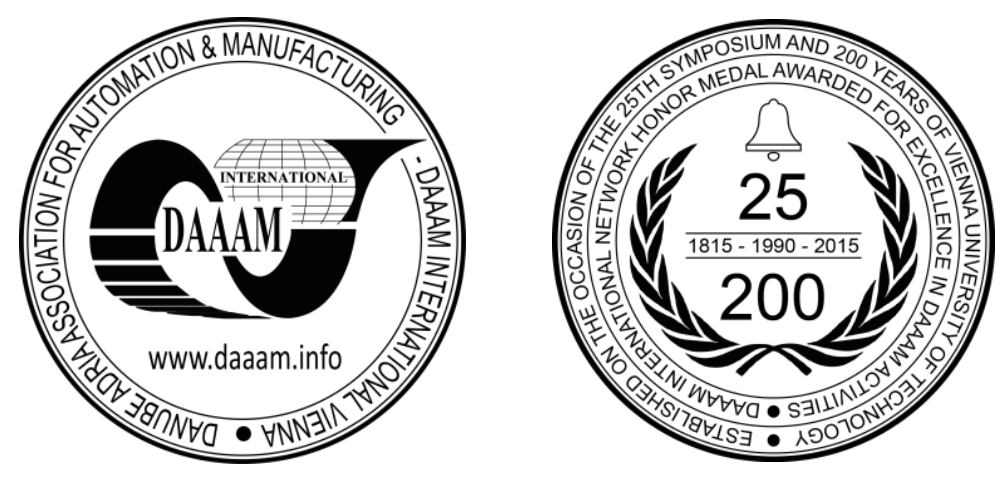

This Publication has to be referred as: Matysek, M[iroslav]; Adamek, M[ilan] \& Karafiat, T[omas] (2016). The Mobile Monitoring and Control of Real Systems, Proceedings of the 26th DAAAM International Symposium, pp.01040108, B. Katalinic (Ed.), Published by DAAAM International, ISBN 978-3-902734-07-5, ISSN 1726-9679, Vienna, Austria

DOI: 10.2507/26th.daaam.proceedings.015 


\section{Introduction}

There are not many professional systems for the remote monitoring and control of simple real systems via LTE, UMTS or GSM GPRS/EDGE data services in Czech Republic.

The mobile monitoring and control system has been exclusively designed for simple real systems with slower events occurrence because of limited response time with mobile or smart phone with LTE data transfer.

This work was inspired with some similarly working mobile phone applications [1], [2], [11], [12], [13]. These applications are programmed in Java language [3], and for example, they are intended for sending SMS to the GSM operators' unpaid SMS portals.

\section{The solution proposal}

The client/server architecture has been chosen for a real system monitoring and control via mobile or smart phone. The client application has been realized in JME again because of its massive support by mobile phone producers [4]. The applications are easily transferable among mobile or smart phones independently from brand or platform [5].

The following main requirements are imposed on the client application:

- It should connect to the server exclusively when needed and send minimum data for sake of low costs

- It sends commands for system setting according to the user requirements

- It receives information on real system latest state, and it displays it on display

The following main requirements are imposed on the server application:

- It coordinates the communication with client

- It receives client commands for the system setting

- It dispatches the information on system current state to the client

- It controls the system according to the client commands

- It reads the latest information from the system

\section{Mobile phone}

There was the mobile phone employed for the system monitoring and control. That mobile phone was applied because it supports all important - Java and UMTS specifications and because of its convenient dimensions unlike some current models big smart phones lower battery life with UMTS [6] or LTE [7].

\section{Smart phone}

The client works on smart phones with Android operating system. In this case, you must download and install a Java emulator, e.g. Java on Android kood apps and Java Manager; Emulate Java JWP Inc. Before installing the emulator Java on Android kood apps is necessary to gain root access.

\section{The real system for testing}

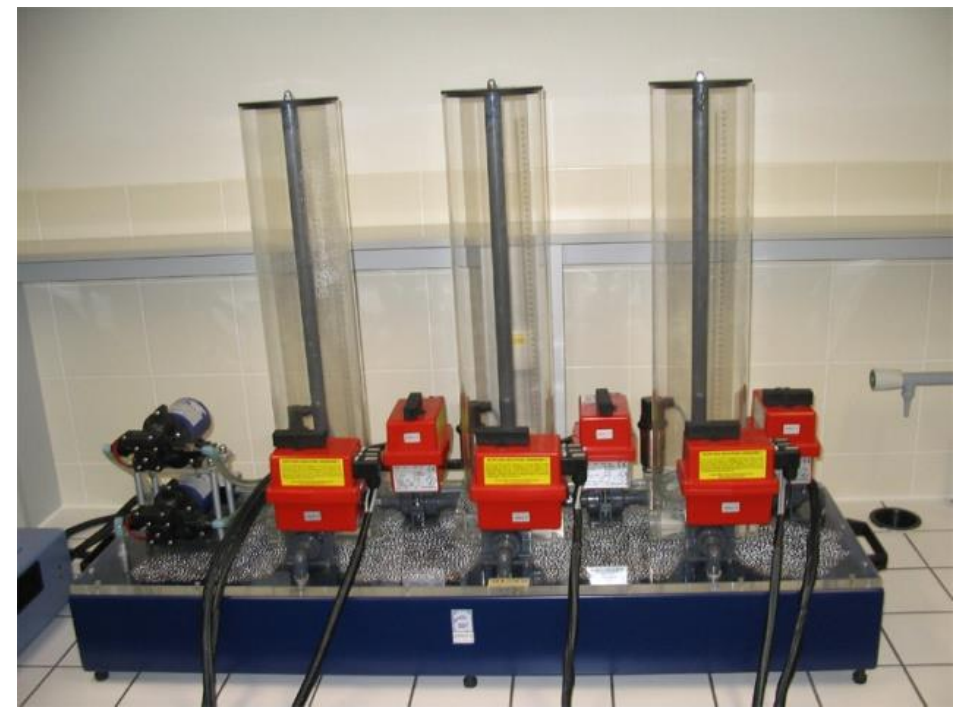

Fig. 1. Real system Amira DTS200 
That real system used for our work results confirmation had been chosen from a couple of reasons. One of those reasons is the results vivid presentation and the other is that the events happening are "slow enough" to be controlled via mobile or smart phone and GSM network.

The water system DTS200 Fig. 1 by Amira company contents three tanks N1, N2, and N3 which are interconnected with valves.

Each tank has an extra valve for draining the tank liquid into a container with exception of N3 that has two drain valves. The pump P1 supplies liquid to the tank N1 and the pump P2 supplies the tank N3.

\section{NetBeans}

The development environment NetBeans IDE (Integrated Development Environment) version 8.0.2 was applied during both the mobile or smart phone application and the PC server application development [8]. The mobile or smart phone application was tested in the environment inbuilt emulator.

\section{Java}

\subsection{Java Development Kit}

The JDK (Java Development Kit) represents the set of basic tools for Java platform application development so that it has to be installed for all Java applications development, including JSE and JME.

\subsection{Java Platform Micro Edition Software Development Kit}

We need JME SDK (it replaces popular Java Wireless Toolkit) besides JDK for the mobile applications in Java.

\subsection{Java Platform Micro Edition Software Development Kit}

Providing we plan exclusively to run Java applications, the JRE (Java Runtime Environment) installation is sufficient

\section{MATLAB}

The adopted real system is commonly controlled from MATLAB environment with Real Time Toolbox support. The necessary drivers are booted easily, and the control is possible from the command line or via the Simulink graphic environment.

\section{Matlabcontrol}

Matlabcontrol is a Java API that facilitates the control and Java applications transaction with local or remote MATLAB sessions.

The Matlabcontrol interface was used for communication with the real system as a remote session in this project. It means that the Java application (the simple server running on the controlling PC in our case) creates a MATLAB session after start and it asks for technological card driver boot. The device linked to the technological card is to be controlled from Java application through MATLAB commands then.

\section{Client application}

The monitoring and control system client application was created as a project in JME NetBeans, CLDC 1.1.1 configuration and MIDP 2.1 profile. Unlike the server application, the client source code covers the user graphic interface and operation. The graphic interface has been created with NetBeans FlowDesigner RAD tool.

\subsection{Start screen}

It is a splashScreen object and it is displayed during application start-up procedure.

\subsection{Main menu}

The list type screen contents main menu items - Monitoring, Controls, Application setup, About system and About application Fig. 2.

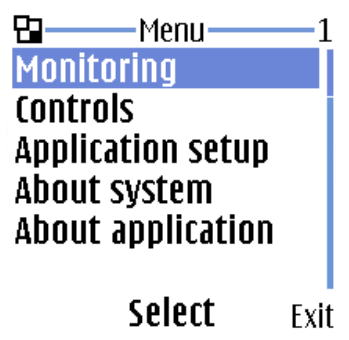

Fig. 2. Main menu and Monitoring submenu on a mobile or smart phone 


\subsection{Forms}

- Monitoring submenu - displays the information about system devices what means tank water level in $\%$, state of pumps and valves Fig. 2

- Controls submenu - offers the possibility to change the system devices state what means to switch on or off pumps, open or close valves Fig. 3

- Application setup submenu - configuration data insertion: IP address, server port, server login name and password Fig. 3

- About system submenu describes briefly the real system to be controlled

- About application submenu lists the application information

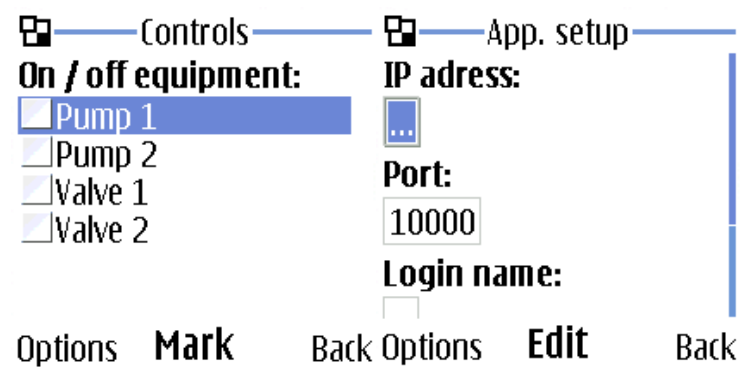

Fig. 3. Controls submenu and Application setup submenu on a mobile or smart phone

\section{Server application}

The monitoring and control system application was created as a project in JSE NetBeans environment.

The server is to be set before the start of first communication with the START button Fig. 4. We should insert values for port (port for the server application), client login name and password. After communication start, the server runs and waits for a client. There are messages about communication state a information and would-be errors displayed in the text information window.

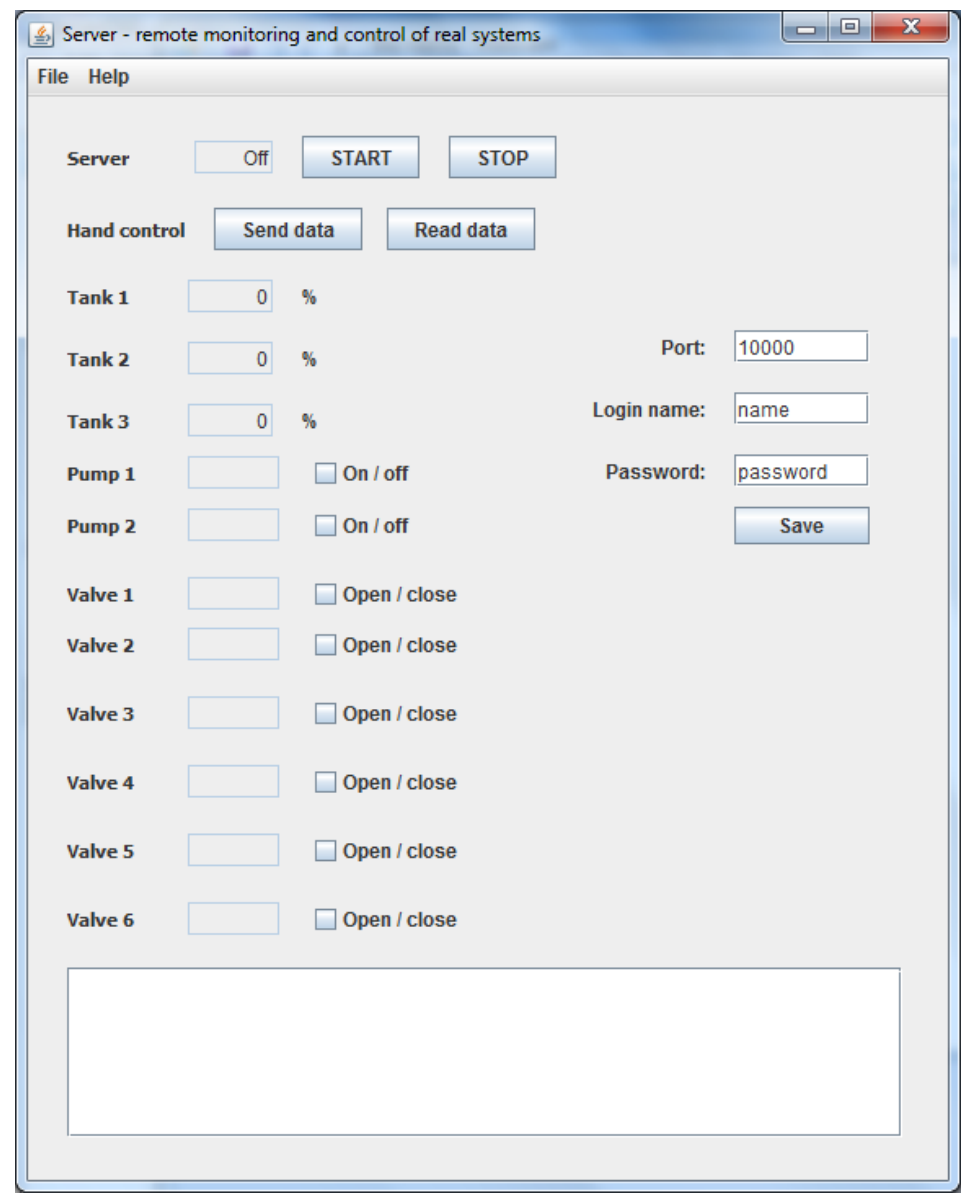

Fig. 4. Server application 


\subsection{Results applicability}

There is basically not necessary to install the application. The JAR (Java ARchive) file execute is enough. We can run the application on any PC with JRE and MATLAB installed. JVM (Java Virtual Machine) must not be firewall blocked if we need the network functions to be exploited, and application PC has to be connected to the internet via public IP address.

\section{Conclusion}

The work goal was to develop the simple mobile monitoring and control system exploiting the LTE, UMTS and GSM GPRS/EDGE data transfer in mobile network.

The costs for the monitoring and control system are very low thanks to mobile data transfer and small data volumes - about $0.8 \mathrm{kB}$ per one monitoring or control.

The mobile or smart phone application is lucid and easily applicable. The server application is easily transferable to the other system in faculty area where majority of systems is controlled via MATLAB. We can modify our application for other systems just by MATLAB command set change so that it can be used for many different purposes, like education, research and ex-faculty applications, e.g. the remote monitoring and control of the central heating in a house.

For reasons the short signal drop outs because of short distance signal fluctuations (the handy in a moving car) and the short drop-out because of radio channel full slots occupation by other network users needs to be taken into account as well, the mobile monitoring and control system is not suitable for fast real systems on GSM GPRE/EDGE networks [9], [10]. In mobile networks UMTS and especially LTE can be used monitoring and control systems faster.

\section{References}

[1] R. Sell, T. Otto, Online engineering for future factory, in: Annals of DAAAM for 2009 \& Proceedings, DAAAM International, Viena, 2009, pp. 1695-1696.

[2] S. Seiler, R. Sell, Approaches to useweb technologies in real applications, in: Annals of DAAAM for 2009 \& Proceedings, DAAAM International, Viena, 2009, pp. 1741-1742.

[3] Q. Mahmoud, Learn Java 2 Micro Edition, Grada Publishing, Praha, 2002.

[4] K. Topley, J2ME in epitome: Reference manual, Grada Publishing, Praha, 2004.

[5] H. Bock, Platform NetBeans: Detailed programming guide, Computer Press, Brno, 2010.

[6] H. Kaaranen, et al., UMTS Networks: Architecture, Mobility and Services, John Wiley \& Sons, Oxford, 2005.

[7] M. Rumney, LTE and the Evolution to 4G Wireless, John Wiley \& Sons, 2009.

[8] A. Buchalcevova, L. Pitka, NetBeans: Development environment, Oeconomica, Praha, 2007.

[9] 3GPP, The Mobile Broadband Standard, GPRS \& EDGE, [cit. 2015-10-15], In: http://www.3gpp.org/technologies/keywords-acronyms/102-gprs-edge.

[10] P. Vacek, Data transmission in mobile networks, ČVUT Praha, [cit. 2015-10-15], In: http://www.elektrorevue.cz/clanky/05046/index.html.

[11] L. Jin-feng, et al., A Novel Remote Monitoring and Control System Based on GSM for Home Security, International Journal of Online Engineering (iJOE), 11.4 (2015) 34-38.

[12] T. Ahmad, et al., Remote Monitoring for Solar Photovoltaic Systems in Rural Application Using GSM Network, International Journal of Emerging Electric Power Systems 16.5 (2015) 413-419.

[13] R. Ionel, et al., Implementation of a GPRS based remote water quality analysis instrumentation, Measurement 65 (2015) 81-93. 